\title{
The Design and Implementation of Tourist Perception Information Service System based on Web
}

\author{
Yan Liu \\ School of Tourism and Service Management, Chongqing University of Education, Chongqing \\ 400065, China \\ 1236679@qq.com
}

Keywords: Web, tourist perception, information service system, design science.

\begin{abstract}
This article is based on an in-depth investigation of tourist information system and its current situation. Taking into consideration the requirements of tourist information system by using the computer science, network technique, the database technique and management principles and methods, we designed the system and database of the tourist perception information service system. This system has a good performance both in function and capability test, and realizes all the desired purposes. More importantly, it realizes the data-sharing function, allowing the visitors to obtain their basic tourism information in time through this system. The system embodies the creed of 'system servicing visitors and tourism servicing system'. Furthermore, it has the advantages of practicality, advancement, integrality, convenience.
\end{abstract}

\section{Introduction}

Tourism electronic commerce is through the use of advanced information technology to improve the internal and external connectivity, travel agencies which improve among tourism enterprises, tourism enterprises and suppliers. And transactions between tourism enterprises and tourists, improve the enterprise internal process, and promote knowledge sharing. The definition of tourism electronic commerce is widely used in the world. It comes from the world Tourism organization UNWTO in its publication "E-Business for Tourism". [1] With the rapid development of communicate information technology and network technology, the popularity of mobile phone terminals, e-commerce is a new kind of model, namely mobile e-commerce. Mobile e-commerce itself has the flexibility, not affected by time and space control. [2] At the same time, the popularity of 3G technology, the electronic information technology combined with the development of the tourism industry characteristics, the influence of the traditional tourism development is immeasurable.

With the development of the society and people's desire for better life, the need of the tourist information service has been continuously increasing. [3] Tourist perception information system construction and management has become a hot topic of the city life in China. With the progress of information technology, more and more scenic spots begin to offer intelligent services; however, the design of intelligent tourist information system is still at the initial stage. How to meet the various needs of different social groups and build an intelligent tourist perception information system is becoming the hot topic for theoretical as well as practical research. In this context, we have designed and developed a tourist perception information service system based on the WEB technical, integrating tourist management, information releasing, and on-line video broadcasting. The purpose of this system is to satisfy visitors' need and to enhance the management of tourism and the quality of visitors' life. It is an experiment for the tourist perception information service system construction, and offers an approach for the tourist perception information system construction.

\section{The Conceptual Model and Background}

Since the 1990s, a new economic model "Electronic Commerce (EC)", which based on Internet, has rapidly covered various industries. In a global context, governments, organizations, enterprises and hundreds of millions of individual users had already participated in E-C activities in diversified 
forms and levels. This has brought the development of EC into a booming era. [4] Undoubtedly, EC has successfully made signif cant changes to the world. After decades of development, however, the world is now in an age of digitalization already and the booming of EC has gradually faded. More and more people have started to think about how to keep the future sustainability of EC. Meanwhile, with the swift and violent advancement of both wireless communication technologies and mobile terminal devices, the vision of "Ubiquitous Computing" is approaching our real life closer and closer. The needs of breaking the time-and-location-limitations of information services and activities keep growing, too. The significant success of EC and the wonderful outlook of Ubiquitous Computing have promoted the development of "Mobile Commerce (MC)" to a large extent.

In an early stage, MC was viewed as a kind of mobile EC, or an extension of EC. Along with the deeper exploration of this field, the difference between EC and MC has become increasingly significant. [5-6] Therefore, more and more scholars and experts incline to separate the research of MC from EC and and have obtained many excellent research results, among which, Tourist perception Mobile Services, one of the new results generated from the Ubiquitous Computing, has pushed the MC to a new high point. Although the trend and fashion of MC now is very similar to the earlier EC, can the legend of MC last long or can MC recreate the glory of EC are challenging questions which have become common focus in both academic field and practical industries. Based on extensively reading of relevant literatures and in-depth study of previous research, we cover four major subjects in this dissertation which are closely related:(I) Mobile Commerce, (2) Tourist perceptionness, (3) Design Science. We discuss the integration of model with design science for tourist perception mobile services.

\section{The Design and Implementation of tourist perception information system}

As shown in Fig. 1, there are four parts in its overall framework of tourist perception information service system. This dissertation proposes a conceptual model oriented to tourist perception mobile services, which are related with value propositions, technical architecture, value network, profit sharing, etc.

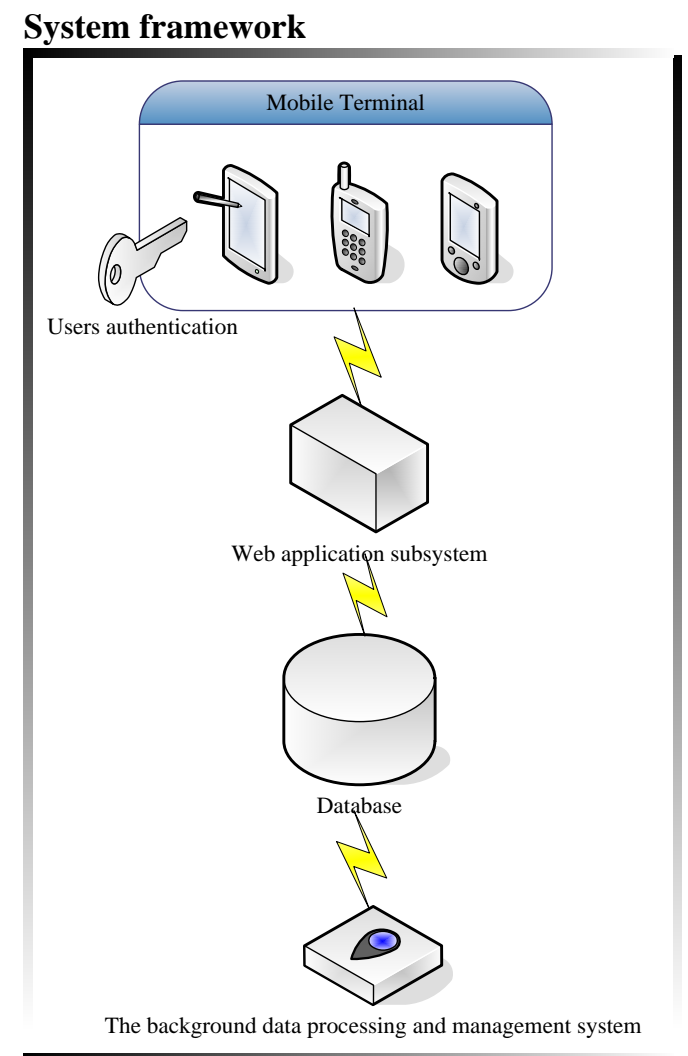

Fig. 1 System framework of tourist perception information service system 
Research on the development methodology and technical framework of tourist perception mobile services. Compared with other information systems, mobility and awareness of tourist perception mobile system seem to be the two aspects that are most significantly different. This dissertation puts forward a development methodology oriented to tourist perception mobile services, and introduces the construction of sensor network, main functions of services, key components, and framework.

The system can be devided into four relaticely independent parts, as shown in Fig. 1, form client to data background respectively is the mobile terminal system, Web application system, database system, the background data processing and management system. The background data processing and management system operate independently, responsible for all kinds of information acquisition and processing browse display format for mobile terminal and write the database, and regular clean of these data that assume the users manage functions. The backstage database system undertake the whole system of data storage, and provide the function of data retrieval and query to Web application system etc.. Web applies subsystem to background database and mobile terminal subsystem, which responds to the mobile phone terminal request, read the information in the database and return to the mobile terminal.

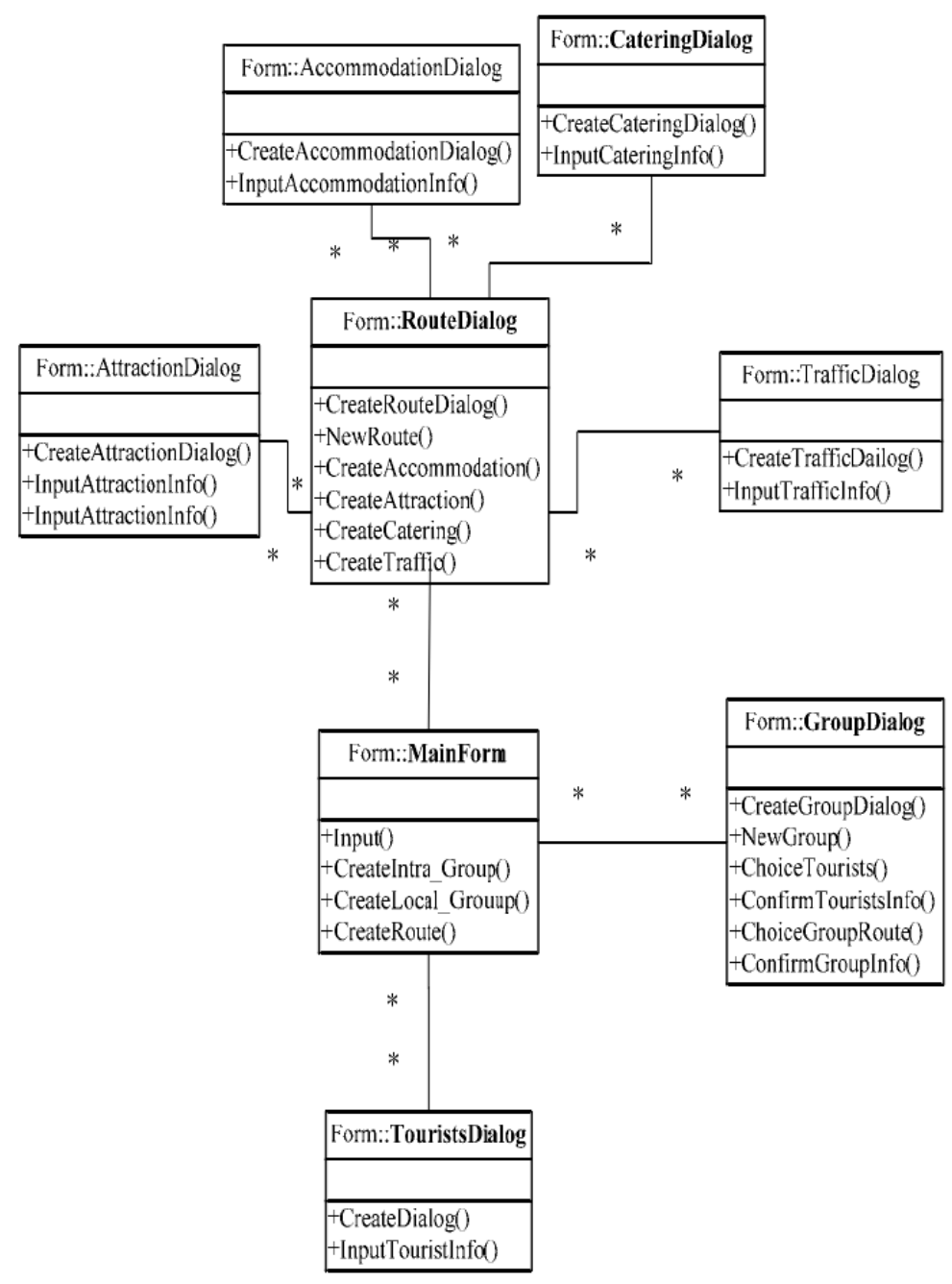

Fig. 2 The main form of the system

The travel agency to manage the daily work of the investigation, collect a lot of information, from the system structure, functions, technical requirements and feasibility and other aspects to consider, I think this subject is an adaptation of the travel agency information management needs of the computer information management system, has a certain practical value and use value. The tourism Digitatizing service platform construction is the main goal of the Web2.0 related technologies and standards, the application of J2EE technology, SQL2005database and other advanced technology, set up tourism service, tourism information services, e-commerce and other functions as one of the 
integrated tourism comprehensive service platform, in order to promote tourism information service level, promote tourism destination the overall marketing promotion, accelerate the development of tourism.

The main form of the system is shown in Fig. 2. The main research contents and tasks are: travel information service system mainly includes the member login module, tourist routes, tourist service module, module business, electronic map, Travel Forum as well as the background management module and other modules. The system adopts the structure of B/S, J2EE component technology, convenient model embedded system, the application system development is flexible, open, serialization and standardization. On the security mechanism of the system, considering the network security, security, security, hardware software data security four.

\section{Work Flow of System}

The back-end data processing and management system is an independent operation; the other three subsystems cooperate with each other to complete the work of the system. When a user operates on a mobile phone, send a data request after operation, the system will work according to the numbering sequence in Fig. 1.

(1) Retrieve mobile phone cache database Sqlite. If Sqlite contains a user request data, then display after reading, complete the response.

(2) If there are no Sqlite data, request through Internet to Web application system.

(3) Web application subsystem is firstly validated user permissions, and then the data retrieval in the back-end database. The retrieved data is returned to the mobile terminal.

(4) The Sqlite cache will return data preservation of mobile terminal to the database, and then display to the users.

\section{Conclusions}

In-depth study of tourism service information field and try to improve the standard of service industries, to enhance the core competitiveness of tourism enterprises and the industry 's influence has important value and significance. We design of a tourist perception information mobile services prototype system with tourism background. The tourism industry is particularly suitable for the application of tourist-aware mobile services, because the tourists are always on the move and wish they can get tourist-related information. This dissertation introduces how to design and develop a tourist-aware tourism prototype system, and through which to verify the development model.

\section{References}

[1] Information on http://mobile.people.com.cn/GB/17057061.htm1

[2] A.K. Dey, and Abowd, G.D. Towards a better understanding of context and context-awareness. Proceedings of Workshop on the What. Who, Where. When and How of Context-Awareness, ACM Press, New York, 2000.

[3] Alan Hevner. Samir Chattee. Chapter 1:Introduction to Design Science Research. Design Research in Information Systems. Integrated Series in Information Systems, 2010, 22(a): 1-8.

[4] Kanwalvir Singh Dhindsa, Himanshu Aggarwal. Mobile Commerce. Standards \& Design Technologies. International Journal of Recent Trends in Engineering, 2009, 22(4).

[5] Alan Hevner. Samir Chatterjee. Chapter 2: Design Science Research in Information Systems. Integrated Series in Information Systems, 2010, 22(b): 9-22.

[6] Alan Hevner. Samir Chatterjee. Chapter 3: Design Science Research Frameworks. Integrated Series in Information Systems, 2010, 22(c): 23-31. 